\title{
Accuracy of Multi-Detector Computed Tomography in Detection of Esophageal Varices in Chronic Liver Disease
}

\author{
Syeda Zakia Shah ${ }^{1}$, Umair Ajmal ${ }^{2}$, Shahabuddin Siddiqui ${ }^{2}$ \\ ${ }^{1}$ Assistant Professor, Department of Radiology, Pakistan Institute of Medical Sciences, Islamabad \\ ${ }^{2}$ Post Graduate Resident, Department of Radiology, Pakistan Institute of Medical Sciences, Islamabad
}

\begin{abstract}
AB S TR ACT
Background: Patients with chronic liver disease should undergo screening endoscopy, but this approach places a heavy burden upon endoscopy units along with other limitations. The aim of this study was to determine the diagnostic accuracy of multi-detector computed tomography scan in detecting esophageal varices taking endoscopy as gold standard.

Material and Methods: This cross-sectional study was done from $1^{\text {st }}$ Jan 2018 to $31^{\text {st }}$ Dec 2018 at Department of Radiology, PIMS Hospital Islamabad. A total of 180 patients of both gender with chronic liver disease for at least 12 months were included in this study with an age range of 25-65 years. Patients with active gastrointestinal hemorrhage, hypersensitivity to iodinated contrast agent, chronic renal failure, claustrophobic and pregnant females were excluded. All the patients underwent endoscopy and computed tomography of lower chest and the upper abdomen before and after intravenous contrast administration. Multi detector computed tomography (MDCT) scan findings for esophageal varices were compared with endoscopy findings.

Results: In MDCT positive patients $(n=102)$, 98 were true positive and 04 were false positive. Among 78 MDCT negative patients, 07 were false negative, whereas 71 were true negative. Overall sensitivity and specificity were $93.33 \%$, and $94.67 \%$ respectively. The positive and negative predictive values were $96.08 \%$ and $91.03 \%$ respectively, while diagnostic accuracy of $\mathrm{MDCT}$ in detecting esophageal varices in chronic liver disease patients was $93.89 \%$, taking endoscopy as gold standard.

Conclusions: Multi-detector computed tomography scan is a highly sensitive and accurate non-invasive modality for detecting esophageal varices in chronic liver disease patients.

Key words: Accuracy, Chronic liver disease, Esophageal varices, Multi-detector computed tomography

\begin{tabular}{lll}
\hline Authors' Contribution: & Correspondence: & Article info: \\
${ }_{1-3}$ Conception; Literature research; Syeda Zakia Shah & Received: May 29, 2019 \\
manuscript design and drafting; Critical Email:sphoolsh@gmail.com & Accepted: February 20, 2020
\end{tabular}

Accepted: February 20, 2020

analysis and manuscript review; Data

analysis; Manuscript Editing.
\end{abstract}

Cite this article. Shah SZ, Ajmal U, Siddiqui S. Accuracy of Multi-Detector Computed

Tomography in Detection of Esophageal Varices in Chronic Liver Disease. J Islamabad Med

Dental Coll.2020; 9(1): 6-11. Doi: 10.35787/jimdc.v9i1.346

Funding Source: Nil

Conflict of Interest: Nil

\section{Introduction}

Portal hypertension is a serious complication of cirrhosis. It is defined as a hepatic venous pressure gradient (HVPG) above $5 \mathrm{~mm} \mathrm{Hg}$. Development of significant complication of portal hypertension i.e. ascites and esophageal and gastric varices results when HVPG increase sabove $10 \mathrm{mmHg}{ }^{1}$ Commonest lethal complication of portal hypertension is variceal bleeding. Gastroesophageal varices are the most common porto-systemic collaterals and their rupture 
results in dangerous variceal bleeding. ${ }^{2}$ The gold standard for identifying the presence and size of varices is esophagogastroduodenoscopy (EGD). Current guidelines recommend EGD to be performed in all patients with cirrhosis at the time of diagnosis and subsequently every 1-2 years, depending on the findings of the first examination and on the severity of cirrhosis. ${ }^{3}$

EGD has high sensitivity and specificity for the presence and grade of varices due to its ability to insufflate air and perform retroflexion in the gastric cardia and fundus. Disadvantages include the need for intravenous sedation, relatively high cost and complications related to its invasive nature. ${ }^{4}$ Many non-invasive or minimally invasive methods have been proposed as alternatives to EGD for screening of varices. The most promising ones are the platelet count (PLT) to spleen diameter ratio, transient elastography, computed tomography (CT), and video capsule endoscopy. ${ }^{5,6}$ In a study carried out on liver cirrhosis patients, esophageal varices were found in $63.16 \%$ patients and MDCT was accurate in detecting esophageal varices with a sensitivity of $86.1 \%$ and specificity of $57.1 \%{ }^{7}$

CT is a non-invasive imaging modality and can be used routinely in general practice for detecting esophageal varices and for selection of timely and proper treatment option in order to reduce the morbidity and mortality of these patients. Since there was controversy in the available literature on diagnostic accuracy of computed tomography scan in detecting esophageal varices, ${ }^{5}$ so this study was conducted to determine the diagnostic accuracy of MDCT in our set up, taking endoscopy as gold standard.

\section{Material and Methods}

This cross-sectional study was done from $1^{\text {st }}$ January 2018 to $31^{\text {st }}$ December 2018 at Department of Radiology, PIMS Hospital Islamabad after approval from institutional ethical committee was taken. A total of 180 patients of both gender with chronic liver disease for at least 12 months were included in this study with an age range of 25-65 years. Patients with active gastrointestinal hemorrhage, hypersensitivity to iodinated contrast agent, chronic renal failure, claustrophobic and pregnant females were excluded. Sample size was calculated by using sensitivity and specificity calculator (Mohd. Ayub Sadiq, School of Dental Sciences, Univerasiti Sains Malaysia), by taking 95\% confidence level with expected prevalence of esophageal varices as $63.16 \%,{ }^{5} 12 \%$ desired precision for sensitivity of $86.1 \%$ and $12 \%$ for specificity of $57.1 \%$ of MDCT scan in detecting esophageal varices. ${ }^{7}$

After taking informed consent, computed tomography of lower chest and the upper abdomen was performed after intravenous contrast administration on Multislice MDCT scanner (Aquilion Toshiba). Three sets of images were acquired in a craniocaudal direction at 25 , 65 , and 180s after injection of the contrast medium. The first acquisition was used for hepatic arterial phase imaging, the second for portal venous phase imaging, and the $3 r d$ acquisition to image the hepatic venous phase. Images were obtained during single breath holding. Each MDCT scan were looked for esophageal varices by an experienced consultant radiologist (experience of at least 5 years). Esophageal varices were considered to be present when enhancing vascular structures within the wall of the esophagus projected into the lumen measuring $\geq 5$ $\mathrm{mm}$. All patients then underwent endoscopy in the gastroenterology department of PIMS by the same consultant. Cherry red and dark red spots on the mucosa of the lower esophagus on endoscopy was taken as positive for esophageal varices.

MDCT scan findings were compared with endoscopy findings. All this data including the demographic data was recorded on a pre-designed 
proforma and analyzed through computer software SPSS version 20.0. Mean and standard deviation were calculated for quantitative variables i.e. age. Frequency and percentage were calculated for qualitative variables i.e. gender and esophageal varices on MDCT scan and endoscopy. A $2 \times 2$ contingency table was used to calculate sensitivity, specificity, positive predictive value, negative predictive value and diagnostic accuracy of MDCT scan in detecting esophageal varices, taking endoscopy as gold standard.

\section{Results}

Patients included in the study had a mean age of $47.57 \pm 10.56$ years and an age range from $25-65$ years. Majority of the patients (52.78\%) were between 46-65 years of age. Regarding gender distribution, 100 (55.56\%) were males and $80(44.44 \%)$ were females with a male-tofemale ratio of 1.25:1.

All the patients were subjected to multidetector computed tomography scan with the diagnosis of esophageal varices in 102 (56.67\%) patients and no esophageal varices in 78 (43.33\%) patients (Figure 1).

Endoscopy findings confirmed esophageal varices in 105 (58.33\%) patients and no esophageal varices in 75 (41.67\%) patients. In MDCT positive patients, 98 (True Positive) had esophageal varices and 04 (False Positive) had no esophageal varices on endoscopy. Among 78 MDCT negative patients, 07 (False Negative) had esophageal varices whereas 71 (True Negative) had no esophageal varices on endoscopy (Table I).

Overall, there was a high sensitivity (93.33\%), specificity (94.67\%), positive predictive value (96.08\%), negative predictive value (91.03\%) and diagnostic accuracy (93.89\%) of multidetector computed tomography scan in detecting esophageal varices in chronic liver disease patients, taking endoscopy as gold standard (Figure 2).

\begin{tabular}{|c|c|c|c|}
\hline & \multicolumn{2}{|c|}{ Result on endoscopy (n) } & \multirow{2}{*}{ Total } \\
\hline & Positive & Negative & \\
\hline $\begin{array}{l}\text { Patients with positive } \\
\text { result on MDCT }\end{array}$ & 98 (TP) & $04(\mathrm{FP})$ & 102 \\
\hline $\begin{array}{l}\text { Patients with } \\
\text { negative result on } \\
\text { MDCT }\end{array}$ & 07 (FN) & $71(\mathrm{TN})$ & 78 \\
\hline Total & 105 & 75 & 180 \\
\hline
\end{tabular}

TP-True Positive; FP-False Positive; TN-True Negative; FN-False Negative

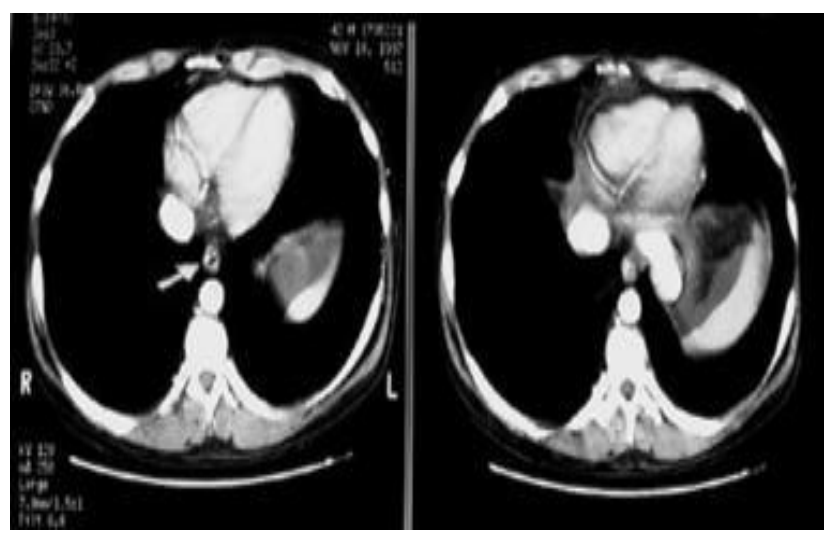

Figure 1: Appearance of esophageal varices on CT. Arrow points to enhancing vascular structures within the wall of the esophagus projecting into the lumen

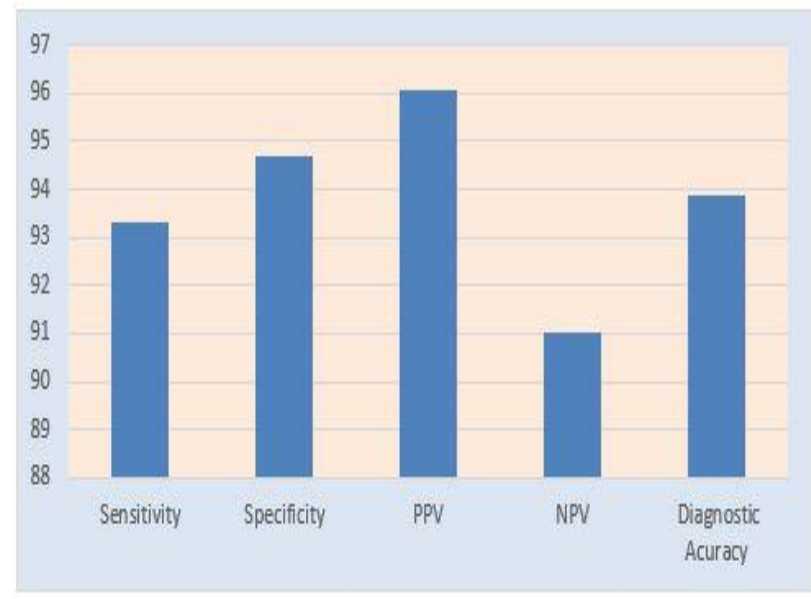

Figure 2: Diagnostic Accuracy of MDCT Scan in Percentages PPV-Positive predictive value; NPV-Negative predictive value 


\section{Discussion}

Early diagnosis of gastroesophageal varices before the onset of first bleed is highly recommended as many studies showed that the risk of variceal bleeding can be reduced from $50 \%$ to $15 \%$ for large esophageal varices. ${ }^{8}$ Esophagogastroduodenoscopy (EGD) is the gold standard in the diagnosis of gastroesophageal varices. However, due to its invasiveness, expense, need for sedation, and patient's poor acceptance of the procedure, the use of endoscopy as a method of screening is limited. 9,10

We conducted this study to determine the diagnostic accuracy of multi -detector computed tomography scan in detecting esophageal varices in chronic liver disease patients, taking endoscopy as gold standard. In our study the overall sensitivity and specificity of computed tomography scan in detecting esophageal varices in chronic liver disease patients, taking endoscopy as gold standard was $93.33 \%$ and $94.67 \%$ respectively. In a study performed by Kammash et al, the overall sensitivity and specificity of MDCT to detect esophageal varices were $99.40 \%$ and $99.60 \%$ respectively. ${ }^{11}$

The sensitivity and specificity of triphasic CT enterography with ingestion of neutral oral contrast material were $42 \%$ and $100 \%$ respectively in the detection of acute $\mathrm{GI}$ bleeding in a recent study by Hara et al. ${ }^{12}$ In a study by Scheffel et al, multidetector CT with arterial and portal phases of contrast enhancement and with no oral contrast material was able to show the bleeding source prospectively in $83 \%$ of patients. ${ }^{13}$

CT can be a good alternative for the detection of varices in cirrhotic patients with HCC, already undergoing local regional treatments. The effectiveness of the treatment and the presence of recurrence are evaluated by CT in these patients and Kim et $\mathrm{al}^{14}$ showed high sensitivity
(91.9\%) and specificity (92.2\%) for the detection of esophageal varices without alteration of the CT protocol. The efficacy of standard thick-slice $\mathrm{CT}$, especially for the detection of large varices, was demonstrated by two studies, ${ }^{15,16}$ without thin slice reconstruction adding accuracy. In addition, like ultrasonography, CT is also an operator-dependent method, but radiologist residents and endoscopists showed similar performance to specialized abdominal radiologists in the detection of large varices. Abdominal radiologists were more efficient in the detection of small varices compared to residents and endoscopists. ${ }^{17}$

CT scan is an excellent method for detecting moderate to large esophageal varices and for evaluating the entire portal venous system. It is a minimally invasive imaging modality that involves the use of only a peripheral intravenous line; therefore, it is a more attractive method than angiography or endoscopy in the evaluation of the portal venous system.

In the only study directly comparing CT with the platelet/spleen diameter ratio, CT proved to have higher sensitivity and specificity. ${ }^{7}$ This method is better tolerated than endoscopy and more readily accepted by patients even in studies where air insufflation was used before performing CT. ${ }^{18}$ Moreover, CT can be simultaneously used as a screening method for $\mathrm{HCC}$ and varices in cirrhotic patients. The main disadvantage of CT is the radiation dose, although, considering the high mean age of cirrhotic patients, the benefits are likely to outweigh the risk of radiation-induced carcinogenesis. ${ }^{19}$ The cost of the method is higher compared to other non-invasive methods, but lower compared to endoscopy. ${ }^{20}$

Several studies have compared CT and endoscopy findings. A cut off point of $5 \mathrm{~mm}$ was previously shown to have approximately $90 \%$ sensitivity and $50 \%$ specificity for large varices. ${ }^{21}$ Another study 
used a 3-mm threshold for varices on CT to accurately predict the presence of large varices on EGD. $^{22}$

According to Deng and his colleagues, the sensitivity and specificity of Contrast Enhanced CT (CECT) scan were $95.56 \%$ and $71.43 \%$, respectively. They concluded that CECT scans have a moderate diagnostic accuracy for esophageal varices in liver cirrhosis. CECT scan might be useful to decrease the use of upper gastrointestinal endoscopy in clinical practice. ${ }^{23}$

CT is an imaging modality that is quite precise in visualization of esophageal varices. CT could detect early HCC and hence is useful in the holistic management of cirrhotics. It is of paramount importance to underline the diagnostic value of CT in early detection of varices. Radiologists should comment on incidental findings of varices even when it is done for other reasons.

Limitation: Intravenous contrast is required for diagnosis of esophageal varices, which may be contraindicated in patients with impaired renal function or allergy to iodine.

\section{Conclusion}

This study concluded that multi-detector computed tomography scan is a highly sensitive and accurate non-invasive modality in detecting esophageal varices in chronic liver disease patients. It has not only dramatically improved our ability to accurately diagnose esophageal varices but also contributed to patients' care with timely and propertreatment. Endoscopy might be reserved mainly for therapeutic purposes. Although this appeared unrealistic a few years ago, advances in technology and more prospective studies could make it feasible in the future.

\section{Recommendations}

We recommend that multi-detector computed tomography (MDCT) should be used routinely as a prime modality for detecting esophageal varices in chronic liver disease patients and in patients not willing for endoscopy. It will result in proper and timely management and will reduce the morbidity and mortality of these patients.

CT can be a good alternative for the detection of varices in cirrhotic patients with HCC, already undergoing loco regional treatments. The effectiveness of the treatment and the presence of recurrence is evaluated by $\mathrm{CT}$ in these patients.

\section{References}

1. Salzl $P$, Reiberger $T$, Ferlitsch $M$, Payer $B A$, Schwengerer $B$, Trauner $M$. et al. Evaluation of portal hypertension and varices by acoustic radiation force impulse imaging of the liver compared to transient elastography and AST to platelet ratio index. Ultraschall Med. 2014; 35(6): 528-33. Doi: 10.1055/s-0034-1366506

2. Masalaite L, Valantinas J, Stanaitis J. Endoscopic ultrasound findings predict the recurrence of esophageal varices after endoscopic band ligation: a prospective cohort study. Scand J Gastroenterol. 2015; 50(11): 1322-30. Doi: 10.3109/00365521.2015.1043640

3. Binţinţan A, Chira RI, Mircea PA. Non-invasive ultrasound-based diagnosis and staging of esophageal varices in liver cirrhosis. A systematic review of the literature published in the third millenium. Med Ultrason. 2013; 15(2): 116-24. Doi: 10.11152/mu.2013.2066.152.ab1ric2

4. Bonilha DQ, Lenz L, CorreiaL M, Rodrigues RA, dePaulo GA, Ferrari AP, et al. Propranolol associated with endoscopic band ligation reduces recurrence of esophageal varices for primary prophylaxis of variceal bleeding: a randomized controlled trial. Eur J Gastroenterol Hepatol. 2015; 27(1): 84-90. Doi: 10.1097/MEG.0000000000000227

5. De Franchis R, Dell'Era A. Invasive and noninvasive methods to diagnose portal hypertension and esophageal varices. Clin Liver Dis. 2014; 18(2): 293 302. Doi: 10.1016/j.cld.2013.12.002

6. Lipp MJ, Broder A, Hudesman D, Suwandhi P, Okon SA, Horowitz $M$, et al. Detection of esophageal 
varices using CT and MRI. Dig Dis Sci. 2011; 56(9): 2696-700. Doi: 10.1007/s10620-011-1660-8

7. Karatzas A, Triantosb C, Kalafatelib M, Marzigieb $M$, Labropoulou-Karatzac C, Thomopoulos K, et al. Multidetector computed tomography versus platelet/spleen diameter ratio as methods for the detection of gastroesophageal varices. Ann Gastroenterol. 2016; 29(1): 71-8. PMID: 26751694

8. Assy N, Rosser BG, Grahame GR, Minuk GY. Risk of sedation for upper $\mathrm{Gl}$ endoscopy exacerbating subclinical hepatic encephalopathy in patients with cirrhosis. Gastrointest Endosc. 1999; 49(6): 690-94. Doi: 10.1016/s0016-5107(99)70283-x

9. Vasudevan $A E$, Goh KL, Bulgiba AM. Impairment of psychomotor responses after conscious sedation in cirrhotic patients undergoing therapeutic upper Gl endoscopy. Am J Gastroenterol. 2002; 97(7): 1717721. Doi: 10.1111/j.1572-0241.2002.05831.x

10. Eisen GM, Baron TH, Dominitz JA, Faigel DO, Goldstein JL, Johanson JF. Complications of upper GI endoscopy. Gastrointest Endosc. 2002; 55(7): 784793. Doi: 10.1016/s0016-5107(02)70404-5

11. Kammash TEL, ELFiky I, Zaiton F, Khorshed SE. Diagnostic performance of multidetector computed tomography in the evaluation of esophageal varices. Egyptian J Radiol Nuclear Med. 2016; 47(1): 43-51. Doi: 10.1016/j.ejrnm.2015.11.003

12. Hara AK, Walker FB, Silva AC, Leighton JA. Preliminary estimate of triphasic $C T$ enterography performance in hemodynamically stable patients with suspected gastrointestinal bleeding. AJR Am J Roentgenol. 2009; 193(5): 1252-260. Doi: 10.2214/ajr.08.1494

13. Scheffel H, Pfammatter T, Wildi S, Bauerfeind $P$, Marincek B, Alkadhi $H$. Acute gastrointestinal bleeding: detection of source and etiology with multi-detector-row CT. Eur Radiol. 2007; 17(6): 1555-565. Doi: 10.1007/s00330-006-0514-9

14. Kim H, Choi D, Gwak GY. High-risk esophageal varices in patients treated with locoregional therapies for hepatocellular carcinoma: evaluation with regular follow-up liver CT. Dig Dis Sci. 2009; 54(10): 2247-52. Doi: 10.1007/s10620-008-0606-2

15. Yu NC, Margolis D, Hsu M, Raman SS, Lu DS. Detection and grading of esophageal varices on liver
CT: comparison of standard and thin-section multiplanar reconstructions in diagnostic accuracy. AJR Am J Roentgenol. 2011; 197(3): 643-49. Doi: 10.2214/AJR.10.5458.

16. Park HS, Kim YJ, Choe WH, Ko SY, Bak SH, II Jung S, et al. Diagnosis of esophageal varices on liver CT: is thin- section reconstruction necessary? Hepatogastroenterol. 2015; 62(138): 333-40. PMID: 25916059

17. Kim H, Choi D, Gwak GY. Evaluation of esophageal varices on liver computed tomography: receiver operating characteristic analyses of the performance of radiologists and endoscopists. J GastroenterolHepatol. 2009; 24(9): 1534-540. Doi: 10.1111/j.1440-1746.2009.05849.x

18. Kim SH, Kim YJ, Lee JM, Choi KD, Chung YJ, Han JK, et al. Esophageal varices in patients with cirrhosis: multidetector CT esophagography-comparison with endoscopy. Radiol. 2007; 242(3): 759-68. Doi: 10.1148/radiol.2423050784

19. D’Amico G, Garcia-Tsao G, Pagliaro L. Natural history and prognostic indicators of survival in cirrhosis: a systematic review of 118 studies. J Hepatol. 2006; 44(1): 217-31. Doi: 10.1016/j.jhep.2005.10.013

20. Lotfipour AK, Douek M, Shimoga SV. The cost of screening esophageal varices: traditional endoscopy versus computed tomography. J Comput Assist Tomogr. 2014; 38(6): 963-67. Doi: 10.1097/RCT.0000000000000147

21. Perri RE, Chiorean MV, Fidler JL. A prospective evaluation of computerized tomographic (CT) scanning as a screening modality for esophageal varices. Hepatol. 2008; 47(5): 1587-594. Doi: 10.1002/hep.22219

22. Kamath PS, Wiesner RH, Malinchoc M, Kremers W, Therneau TM, Kosberg CL et al. A model to predict survival in patients with end-stage liver disease. Hepatol. 2001; 33(2): 464-70. Doi: 10.1053/jhep.2001.22172

23. Deng H, Qi X, Zhang Y, Peng Y, Li J, Guo X. Diagnostic accuracy of contrast-enhanced computed tomography for esophageal varices in liver cirrhosis: a retrospective observational study. J Evid Based Med. 2017; 10(1): 46-52. Doi: 10.1155/2019/670467 